\title{
BMJ Open Experience and awareness of research integrity among Japanese physicians: a nationwide cross-sectional study
}

Rie Nishimura, ${ }^{1}$ Jiro Takeuchi (D) , ${ }^{1}$ Mio Sakuma, ${ }^{1}$ Kazutaka Uchida, ${ }^{1,2}$ Miki Higaonna, ${ }^{3}$ Norito Kinjo, ${ }^{1,2}$ Fumihiro Sakakibara (1) ,1,2 Tsukasa Nakamura, ${ }^{4}$ Shinji Kosaka, ${ }^{5}$ Shinichi Yoshimura, ${ }^{2}$ Shinichiro Ueda, ${ }^{6}$ Takeshi Morimoto (1) ${ }^{1}$

To cite: Nishimura R, Takeuchi J, Sakuma M, et al. Experience and awareness of research integrity among Japanese physicians: a nationwide crosssectional study. BMJ Open 2021;11:e052351. doi:10.1136/ bmjopen-2021-052351

\section{- Prepublication history and} additional supplemental material for this paper are available online. To view these files, please visit the journal online (http://dx.doi.org/10.1136/ bmjopen-2021-052351).

Received 13 April 2021 Accepted 14 September 2021

\section{Check for updates}

(c) Author(s) (or their employer(s)) 2021. Re-use permitted under CC BY-NC. No commercial re-use. See rights and permissions. Published by BMJ.

${ }^{1}$ Department of Clinical Epidemiology, Hyogo College of Medicine, Nishinomiya, Japan ${ }^{2}$ Department of Neurosurgery, Hyogo college of Medicine, Nishinomiya, Japan

${ }^{3}$ School of Health Sciences, Faculty of Medicine, University of the Ryukyus, Nishihara, Japan ${ }^{4}$ Department of Infectious Diseases, Shimane Prefectural Central Hospital, Izumo, Japan ${ }^{5}$ Shimane Prefectural Central Hospital, Izumo, Japan

${ }^{6}$ Department of Clinical

Pharmacology and Therapeutics, University of the Ryukyus,

Nishihara, Japan

Correspondence to

Professor Takeshi Morimoto;

morimoto@kuhp.kyoto-u.ac.jp

\section{ABSTRACT}

Objectives To explore the awareness and practice of clinical research integrity among Japanese physicians. Design A nationwide cross-sectional study conducted in March 2020.

Setting All hospitals in Japan.

Participants Physicians aged $<65$ years who work at hospitals participated in clinical research over the past 5 years. The sample was stratified according to geographical location and subspecialty, and 1100 physicians were proportionally selected.

Primary and secondary outcome measures Knowledge and awareness of research integrity.

Results Among the 1100 participants, $587(53 \%)$ had the experience of being the first author, 299 (27\%) had been co-authors only and 214 (19\%) had no authorship. A total of 1021 (93\%) had experienced learning research integrity, and $555(54 \%)$ became aware of research integrity. The experience of learning about research integrity was highest among those with first authorship (95\%) and lowest among those without authorship (89\%) $(p=0.003)$. The majority of participants learnt about research integrity for passive reasons such as it being 'required by the institution' (57\%) or it being 'required to obtain approval of institutional review board (IRB)' (30\%). Potentially inappropriate research behaviours were observed in participants, with $11 \%$ indulging in copying and pasting for writing the paper, $11 \%$ for gifted authorship and 5.8\% for the omission of IRB approval. Factors significantly associated with copying and pasting were being below 40 years old (OR: $1.84 ; 95 \% \mathrm{Cl}: 1.05$ to 3.26 ), being the first presenter (OR: $1.64 ; 95 \% \mathrm{Cl}: 1.05$ to 2.57 ) or having passive reasons for learning research integrity (OR: 2.96; $95 \% \mathrm{Cl}: 1.57$ to 5.59). Furthermore, gifted authorship was significantly associated with being a c0-author only (OR: 1.84; $95 \% \mathrm{Cl}: 1.18$ to 2.87 ) and having passive reasons for learning about research integrity (OR: 1.79; 95\% Cl: 1.03 to 3.12 ).

Conclusions Most physicians conducting clinical research have learnt about research integrity, but potentially inappropriate research behaviours are associated with passive reasons for learning.

\section{INTRODUCTION}

Research integrity has become a global concern, and world conferences on research

\section{STRENGTHS AND LIMITATIONS OF THIS STUDY}

$\Rightarrow$ This is the first study to estimate the prevalence and factors of potentially inappropriate research behaviours among physicians who conducted research.

$\Rightarrow$ This is a nationwide cross-sectional study of physicians in various specialties and geographical location throughout Japan.

$\Rightarrow$ By conducting anonymous web-based study, it is likely to collect the honest answers for ethically sensitive questionnaires from a large sample.

$\Rightarrow A$ cross-sectional study with self-reported questionnaires lacks the validation of actual behaviour or awareness, and recall bias is also unavoidable.

integrity are constantly being held. 'World Conferences on Research Integrity' has defined research integrity as 'the principles and standards that have the purpose to ensure validity and trustworthiness of research'. ${ }^{1}$ To discuss research integrity, Steneck categorises research behaviour into three categories: (1) fabrication, falsification and plagiarism (FFP), (2) questionable research practice (QRP) and (3) responsible conduct of research. ${ }^{2}$ The US Office of Science and Technology Policy defined FFP as research misconduct in $2000,{ }^{3}$ and many countries have adopted the same definition. ${ }^{4}$

A recent meta-analysis found that 2\%-14\% of scientists in high-income countries may have fabricated or falsified data. ${ }^{5}$ Despite this statistic, unethical research behaviour is not limited to FFPs. QRPs are behaviours that are considered harmful because of the risk of misleading consequences ${ }^{6}$ and are also included in unethical research behaviour. ${ }^{7}$ However, not all QRPs are considered harmful and should be interpreted in the appropriate context. ${ }^{7}$ Therefore, it is important to develop the necessary skills to judge research activities from the perspective of research integrity. 
Some countries that fund national research activities have their own misconduct policies. ${ }^{4}$ In these cases, education on research integrity is often implemented, ${ }^{8}$ although it has been reported that these measures fail to improve research integrity. ${ }^{8}$ For example, Scandinavian studies reported that up to $4.9 \%$ of $\mathrm{PhD}$ students witnessed fabricated data and implied that the purpose of education on research integrity had failed. ${ }^{9}$ Studies investigating the prevalence or effectiveness of educational programmes on research integrity have mainly focused on $\mathrm{PhD}$ or undergraduate students, and those that consider advanced researchers or physicians are generally lacking. The lack of effectiveness of education on research integrity in clinical research is crucial because (1) clinical research involves human lives, (2) research fraud threatens the safety and effectiveness of clinical practices for patients ${ }^{10}$ and (3) many investigators of clinical research are physicians who should uphold the ethical standards of patient care and science. ${ }^{11-13}$

Clinical research is conducted not only in university hospitals but also in general hospitals worldwide. However, reports of educational programmes for research integrity originated from universities or research institutes, ${ }^{14}$ and the actual aspects of research integrity education are uncertain, especially in the field of clinical medicine. Analysing these issues not only in university hospitals or institutions but also in general hospitals is important for promoting clinical research with ethical and scientific integrity. Thus, we conducted a nationwide cross-sectional study to investigate the experiences of education on research integrity among physicians who have conducted clinical research, as well as their awareness of research integrity. We also explored the associations between experience and awareness to develop a better educational programme of research integrity among physicians.

\section{METHODS}

\section{Study design and participants}

We conducted a nationwide cross-sectional study of practising physicians in Japan. The inclusion criteria were physicians who worked at hospitals with at least 200 beds and were under 65 years of age. The threshold of 65 years was determined by the retirement age at university and public hospitals. Those who had not worked on clinical research (other than case reports) over the past 5 years were excluded from this study.

Participants' responses were obtained using the commercial internet study service of Macromill Carenet (https://www.macromillcarenet.jp), which had a panel of 113912 physicians registered in March 2020. The Macromill Carenet emailed the URL of the questionnaire to 45000 registered physicians, who were randomly selected to stratify the geographical location and subspecialty. Keeping the stratification in place, the first 1100 physicians who met the criteria and answered all the questions were included in this closed e-survey. While all URLs sent to invited physicians had unique IDs to avoid duplicate responses, we did not use cookies or store IP addresses. The answering system was initiated at 16:00 on 25 March 2020 and closed automatically when a predetermined sample size was achieved in each stratum at 16:00 on 27 March 2020. The participants anonymously provided their answers through the website, and the incentive for participation was electronic money equivalent to £3.30. The responses from the participants were stored on the secured server of Macromill Carenet. To reduce the nonresponse bias, we described the study purpose (academic use), name of the principal investigator, study body and grant from government agency on the URL. We also ensure that the system did not allow for 'no response' in any item.

\section{Questionnaire}

We developed the questionnaire items with reference to existing studies on research misconduct (online supplemental file 1). ${ }^{41516}$ The questionnaire consisted of the experience and awareness of research activities (including publishing papers and presenting abstracts at any conferences) and integrity, as well as participants' characteristics (including age category and type of institution). Participants were asked about their experience of learning about research integrity, reasons for learning about it and their awareness of it. The awareness of the research integrity was assessed based on the following eight domains from a previous report ${ }^{17}$ : (1) autonomy of study subjects, (2) safety of study subjects, (3) appropriate record and store of study data, (4) completeness of image creations, (5) checks for FFP, (6) management of conflict of interest, (7) appropriateness of authorship and (8) transparency of organisational relationships. We asked participants if they knew the following policies by the Japanese government: the Ethical Guidelines for Medical and Health Research Involving Human Subjects, ${ }^{18}$ Clinical Trials Act $^{19}$ and other policies issued by ministries, including the Ministry of Education, Culture, Sports, Science and Technology, the Japan Science and Technology Agency, and the Japan Agency for Medical Research and Development.

Finally, we asked participants about their experiences of potentially inappropriate research behaviours, including (1) copying and pasting from other manuscripts (copying and pasting); (2) becoming a co-author without any involvement in conducting the research or drafting the manuscript (gifted authorship) and (3) presenting or writing research papers without approval from the institutional review boards (omission of IRB approval).

Because the questionnaire items were sensitive experiences or attitudes related to potentially inappropriate research behaviour, no gold standard was available and conducting an anonymous pilot study was not realistic; we analysed the questionnaire items using content validity. The final questionnaire was fixed after nine revisions through discussions among the study investigators.

The questionnaire items consisted of categorical or ordinal variables. The ordinal variables were measured using six-point Likert scale and were then dichotomised, 
with the upper two categories defined as proactive answers and the other categories as passive answers. This was because usually, there is a tendency of participants to answer sensitive questions with a neutral response, and the Japanese prefer ambiguous responses in general. ${ }^{20}$ The 36 subspecialties used for stratification were categorised as internal medicine, surgery or 'others' for analyses.

\section{Statistical analysis}

Categorical variables were presented as numbers and percentages. We divided participants into those who had experiences of first authorship (first author), co-authorship only (co-author only) and neither (no author) over the past 5 years. We then compared the characteristics, experiences and reasons for learning research activities, awareness of research activities, knowledge of governmental policies and experience of potentially inappropriate research behaviours between these groups using the $\chi^{2}$ test. We also explored the relationship between awareness of research integrity and other factors using the $\chi^{2}$ test.

We constructed multivariable logistic regression models to explore the factors associated with potentially inappropriate research behaviours. The independent variables were theoretically determined as age, institution, research activity, passive reasons for learning about research integrity (combination of 'required by the institution' and 'required to obtain approval from IRB') and recalling learning content. All the variables were simultaneously included without model selection.

Two-tailed $\mathrm{p}$ values less than 0.05 were considered statistically significant. All statistical analyses were conducted using JMP Version 14.2 (SAS Institute, Cary, North Carolina, USA). The technical set-up of the website was such that it did not allow missing data, and thus, no data were missing.

\section{RESULTS}

\section{Experience of research activity}

Among the 45000 physicians who were invited, 1815 physicians accessed the URL of the study. During the screening process, 715 physicians who did not meet the inclusion criteria or failed to complete the questionnaire were excluded, and 1100 physicians (response rate: $60.6 \%$ ) who completed the questionnaire were included in the study. Participants' ages ( $34 \%$ aged under 40 years, $32 \%$ aged $40-50$ years and $34 \%$ aged 50 years or older) and affiliated hospitals (35\% university hospitals or institutes, $29 \%$ public hospitals and $36 \%$ private hospitals) were well balanced (table 1). Among the participants, $587(53 \%)$ had experienced being the first author, 299 $(27 \%)$ had only experienced co-authors and $214(19 \%)$ had experienced neither.

Among participants who were less than 40 years old or between 40 years old and 50 years old, $58 \%$ (219/376) and $62 \%(218 / 353)$ had been first authors, respectively. Those without authorship (no author) made up 12\%
(42/353) of the participants between 40 years old and 50 years old, and those that were co-author only were prevalent among the participants who were more than 50 years old. First author was prevalent among those affiliated with a university hospital or institute, and lack of authorship was prevalent among those affiliated with private hospitals.

A total of 1021 (93\%) participants had experienced learning about research integrity. The experience of learning about research integrity was significantly different between affiliations (university hospitals or institutes: 381/384 (99\%); public hospitals: 305/324 (94\%); private hospitals: 335/392 (85\%); p<0.0001). While 540 out of $1021(53 \%)$ participants remembered the content of the course, 555 out of $1021(54 \%)$ became aware of the integrity of their research after learning. Experience of learning research integrity was highest among those with first author experience $(95 \%)$ and lowest among those without authorship experience $(89 \%)(\mathrm{p}=0.003)$. This trend was consistent with recalling learning and awareness of research integrity after learning. The differences between first authors, co-authors only and no author were statistically significant $(\mathrm{p}<0.0001)$.

The majority of participants learnt research integrity for passive reasons, including it being 'required by the institution' $(57 \%)$ or 'required to obtain approval of IRB' $(30 \%)$. However, there were a few active reasons, such as 'considering it a necessity to learn about research integrity' (16\%) and being 'interested in learning about research integrity' $(9.7 \%)$. Participants with first author experience were more likely to have reasons for being 'required by the institution' or 'required to obtain approval from IRB' than other participants. The number of participants who reported being 'interested in learning about research integrity' was significantly higher among those without either kind of authorship (first author: $5.5 \%$; co-author only: $11 \%$; no author: $20 \%$; $\mathrm{p}<0.0001$ ).

Knowledge of the Ethical Guidelines for Medical and Health Research Involving Human Subjects, Clinical Trials Act, and other policies issued by ministries were not well known among physicians, and those with first author experience were more familiar with them than their counterparts $(\mathrm{p}<0.0001)$.

Potentially inappropriate research behaviours were observed in participants, with $11 \%$ participants admitting to copying and pasting, $11 \%$ admitting to gifted authorship and $5.8 \%$ admitting to the omission of IRB approval. In these cases, there were no significant differences between participants with the first author, co-author only and no author (table 1).

\section{Awareness of research integrity}

Among the eight domains of research integrity, 'appropriate record and store of study data' had the greatest awareness (69\%) and 'transparency of organisational relationships' had the least awareness (16\%) (table 2). Within awareness, 'autonomy of study subjects (61\%)', 'safety of study subjects $(65 \%)$ ', 'appropriate record and store 
Table 1 Characteristics and experiences of participants stratified by authorship

\begin{tabular}{|c|c|c|c|c|c|}
\hline Variables & All $(n=1100)$ & $\begin{array}{l}\text { First author } \\
(\mathrm{n}=587)\end{array}$ & $\begin{array}{l}\text { Co-author } \\
\text { only }(n=299)\end{array}$ & $\begin{array}{l}\text { No author } \\
(\mathrm{n}=214)\end{array}$ & $P$ values \\
\hline \multicolumn{6}{|l|}{ Age category } \\
\hline Aged $<40$ years, $n(\%)$ & $376(34)$ & $219(37)$ & $63(21)$ & $94(44)$ & \multirow[t]{3}{*}{$<0.0001^{*}$} \\
\hline Aged $40-50$ years, $n(\%)$ & $353(32)$ & $218(37)$ & $93(31)$ & $42(20)$ & \\
\hline Aged 50 years or older, $\mathrm{n}(\%)$ & $371(34)$ & $150(26)$ & $143(48)$ & $78(36)$ & \\
\hline \multicolumn{6}{|l|}{ Specialty } \\
\hline Internal medicine, $\mathrm{n}(\%)$ & $518(47)$ & $269(46)$ & $145(48)$ & $104(49)$ & \multirow[t]{3}{*}{$0.02^{*}$} \\
\hline Surgery, n (\%) & $308(28)$ & $176(30)$ & $89(30)$ & $43(20)$ & \\
\hline Others, n (\%) & $274(25)$ & $142(24)$ & $65(22)$ & $67(31)$ & \\
\hline \multicolumn{6}{|l|}{ Institution } \\
\hline University hospital or institute, n (\%) & $384(35)$ & $269(46)$ & $78(26)$ & $37(17)$ & \multirow[t]{3}{*}{$<0.0001^{*}$} \\
\hline Public hospital, n (\%) & $324(29)$ & $147(25)$ & $107(36)$ & $70(33)$ & \\
\hline Private hospital, n (\%) & $392(36)$ & $171(29)$ & $114(38)$ & $107(50)$ & \\
\hline Experience of learning of research integrity, $n$ (\%) & $1021(93)$ & $559(95)$ & $272(91)$ & $190(89)$ & $0.003^{*}$ \\
\hline Recalling learning of research integrity, $n(\%)$ & $540 / 1021(53)$ & $328 / 559(59)$ & $135 / 272(50)$ & $77 / 190(41)$ & $<0.0001^{*}$ \\
\hline Awareness of research integrity after learning, $n(\%)$ & $555 / 1021(54)$ & $339 / 559(61)$ & $148 / 272(54)$ & $68 / 190(36)$ & $<0.0001^{*}$ \\
\hline \multicolumn{6}{|l|}{ Reasons to learn research integrity $\dagger$} \\
\hline Required by the institution, $\mathrm{n}(\%)$ & $582 / 1021(57)$ & $344 / 559(62)$ & $146 / 272(54)$ & $92 / 190(48)$ & $0.003^{*}$ \\
\hline $\begin{array}{l}\text { Recommended by academic association for } \\
\text { certification, } \mathrm{n}(\%)\end{array}$ & $272 / 1021(27)$ & $157 / 559(28)$ & $70 / 272(26)$ & 45/190 (24) & 0.45 \\
\hline Required to obtain approval of IRB, n (\%) & $308 / 1021(30)$ & $180 / 559(32)$ & 68/272 (25) & $60 / 190(32)$ & 0.09 \\
\hline $\begin{array}{l}\text { Consider necessity of learning of research integrity, } n \\
\text { (\%) }\end{array}$ & $161 / 1021(16)$ & $74 / 559(13)$ & $48 / 272(18)$ & $39 / 190(21)$ & $0.04^{*}$ \\
\hline Interested in learning of research integrity, n (\%) & 99/1021 (9.7) & $31 / 559(5.5)$ & $30 / 272(11)$ & 38/190 (20) & $<0.0001^{*}$ \\
\hline \multicolumn{6}{|l|}{$\begin{array}{l}\text { Knowledge of each of the following regulations related to } \\
\text { research integrity in Japant }\end{array}$} \\
\hline $\begin{array}{l}\text { Ethical Guidelines for Medical and Health Research } \\
\text { Involving Human Subjects, } \mathrm{n}(\%)\end{array}$ & $475(43)$ & $306(52)$ & $115(38)$ & $54(25)$ & $<0.0001^{*}$ \\
\hline Clinical Trials Act, n (\%) & $410(37)$ & $268(46)$ & $99(33)$ & $43(20)$ & $<0.0001^{*}$ \\
\hline Policies issued by the ministries, $\mathrm{n}(\%)$ & $334(30)$ & $223(38)$ & $77(26)$ & $34(16)$ & $<0.0001^{*}$ \\
\hline \multicolumn{6}{|l|}{ Experienced $\dagger$} \\
\hline Copying and paste for writing paper, n (\%) & $124(11)$ & $72(12)$ & $28(9.4)$ & $24(11)$ & 0.42 \\
\hline Become gifted authorship, n (\%) & $125(11)$ & $57(9.7)$ & $45(15)$ & $23(11)$ & 0.07 \\
\hline $\begin{array}{l}\text { Presenting or writing research paper without approval } \\
\text { from IRB, } n(\%)\end{array}$ & $64(5.8)$ & $42(7.2)$ & $14(4.7)$ & $8(3.7)$ & 0.11 \\
\hline
\end{tabular}

from IRB, n (\%)

*Statistically significant.

†Multiple answers were allowed.

IRB, Institutional review board.

of study data (75\%)', 'completeness of image creation $(41 \%)$ ', 'management of conflict of interest (63\%)' and 'appropriate authorship (31\%)' were significantly well recognised among participants aged 50 years or older. 'Recalling learning content after learning research integrity' was significantly associated with all eight domains of research integrity. Knowledge of policies related to research integrity (Ethical Guidelines, Clinical Trials Act, and policies of ministries) was also significantly associated with these eight aspects.

\section{Factors associated with potentially inappropriate research behaviours}

Factors that were significantly associated with conducting copying and pasting for writing a paper were being under 40 years of age (OR: 1.84; 95\% CI: 1.05 to 3.26), being first presenters (OR: 1.64; 95\% CI: 1.05 to 2.57 ) and having passive reasons for learning research integrity (OR: 2.96; 95\% CI: 1.57 to 5.59). Furthermore, those affiliated with university hospitals were less likely to conduct copying and pasting than those affiliated with private 


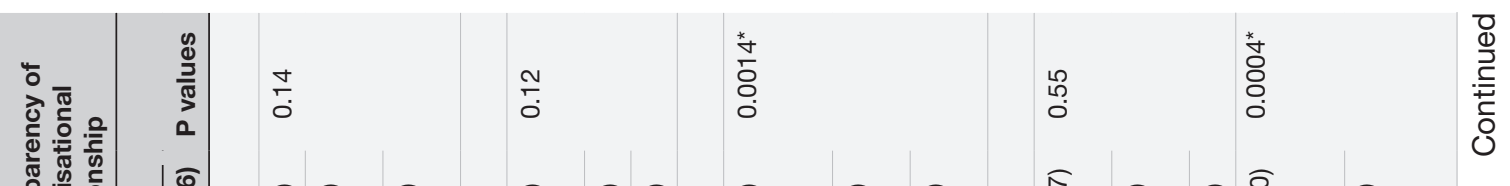

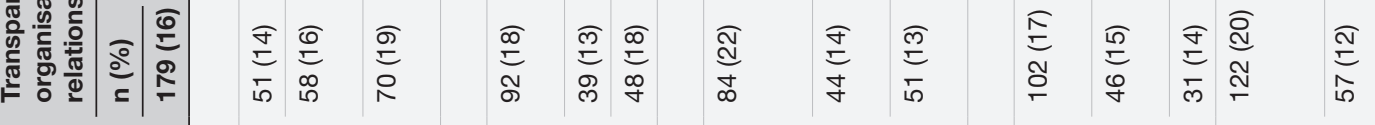

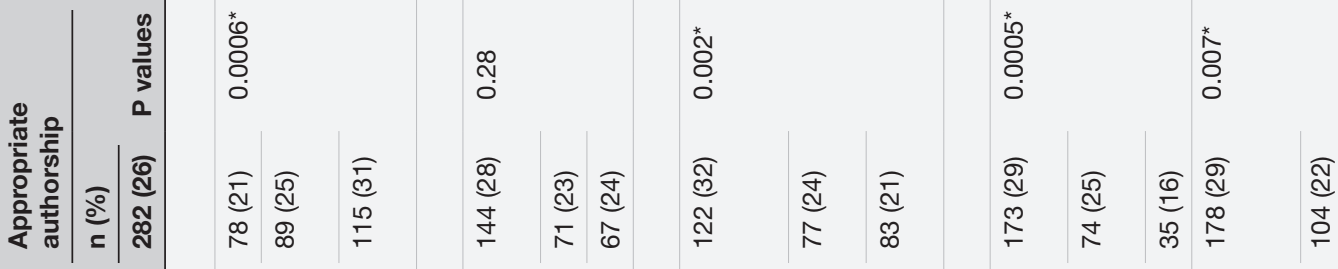

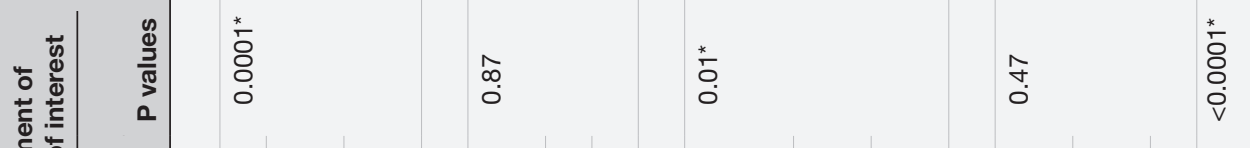

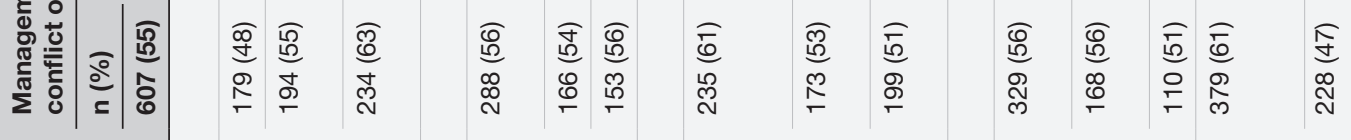

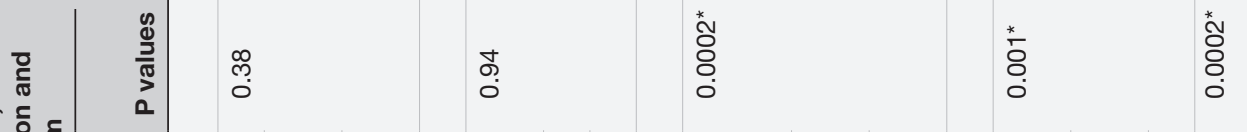

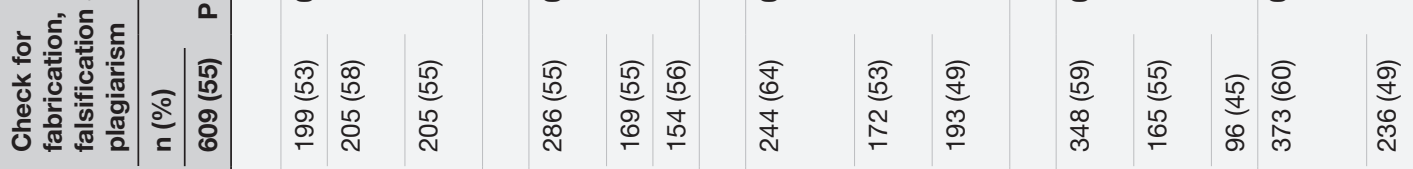

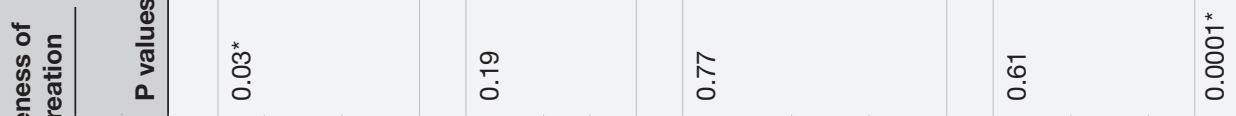

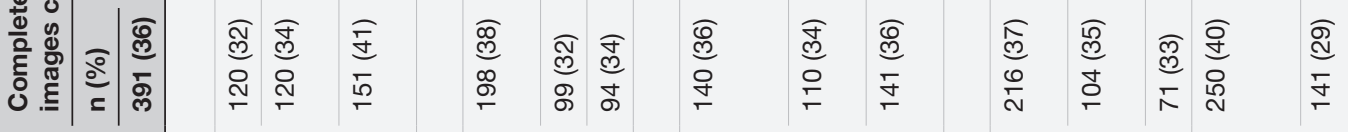

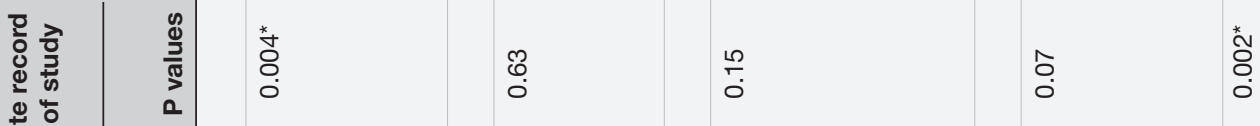

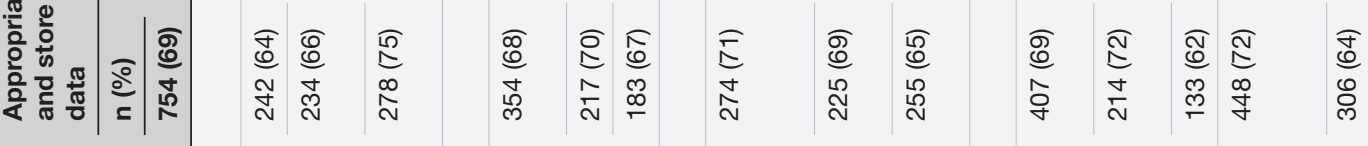

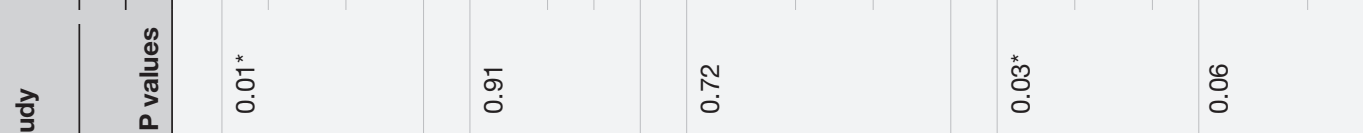

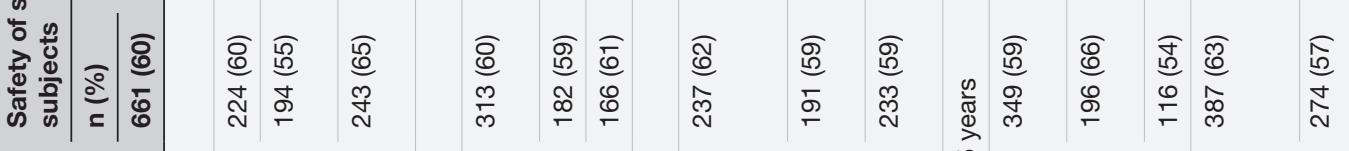

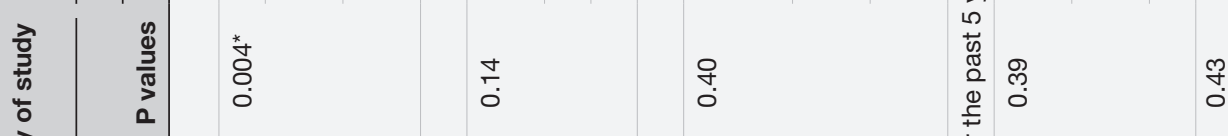

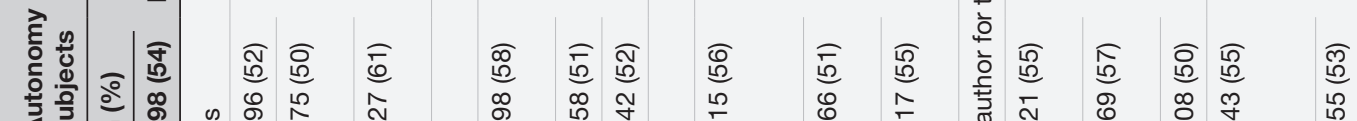

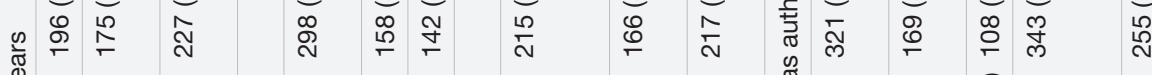

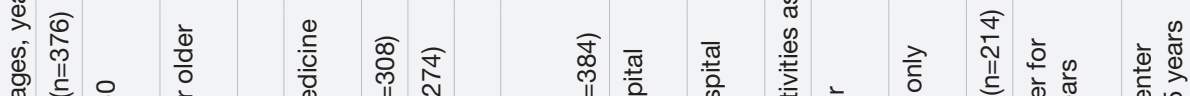

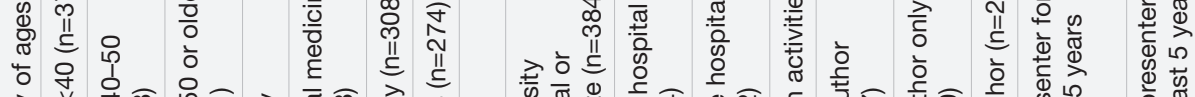

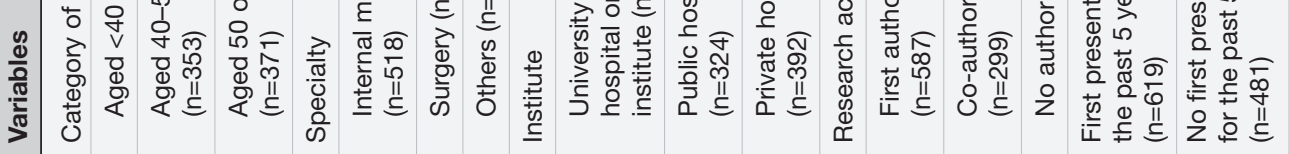




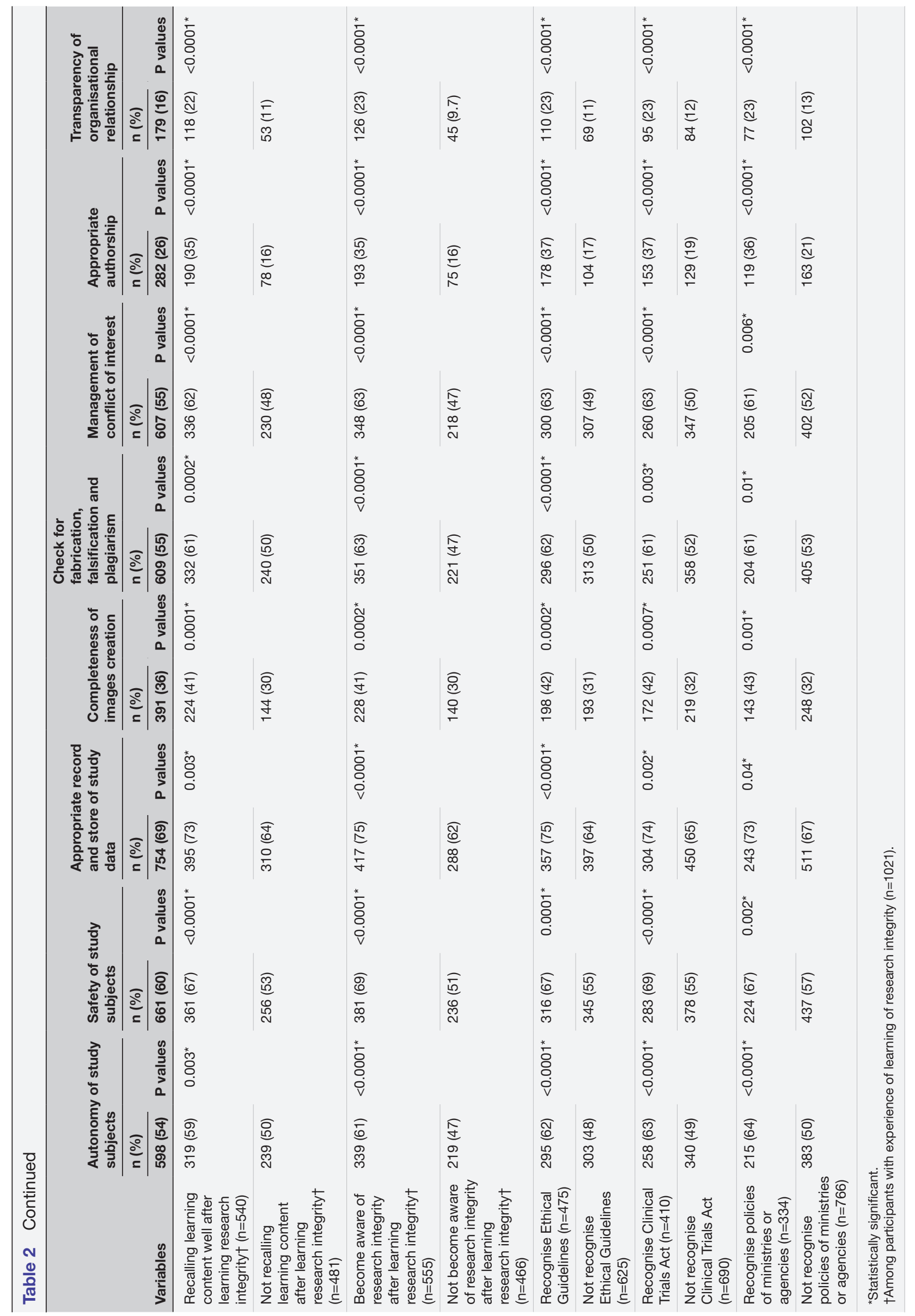




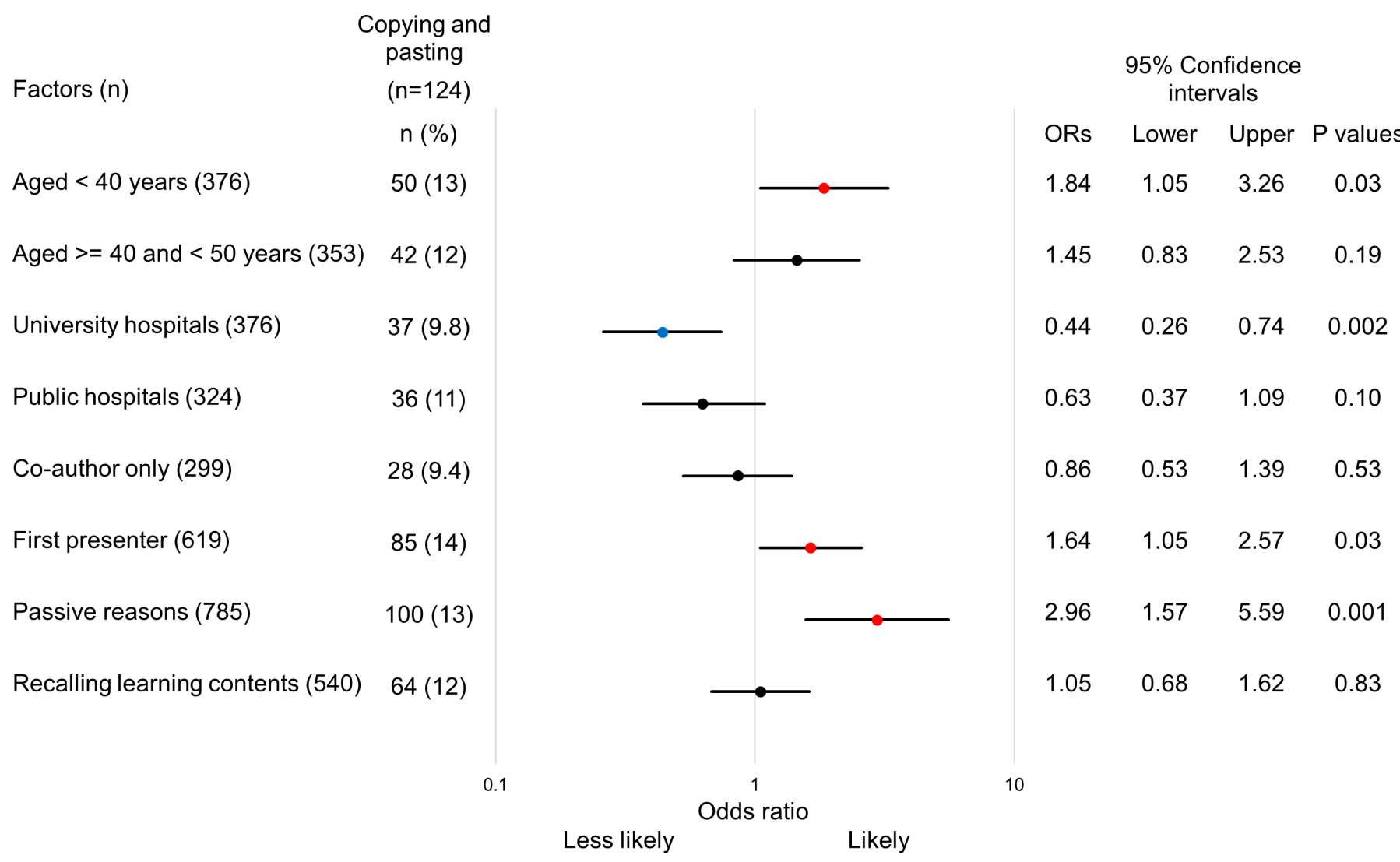

Figure 1 Factors associated with copying and pasting. The horizontal bars indicate the 95\% confidence intervals, and the points on the bars indicate the adjusted odds ratios (ORs). X-axis is an exponential scale.

hospitals or institutes (OR: 0.44; 95\% CI: 0.26 to 0.74 ) (figure 1). Gifted authorship was also significantly associated with co-author only (OR: 1.84; 95\% CI: 1.18 to 2.87) and passive reasons for learning research integrity (OR: 1.79; 95\% CI: 1.03 to 3.12) (figure 2). Categorised age, affiliations, roles in manuscripts or presentations, passive reasons and recalling learning content after learning research integrity were not significantly associated with the omission of IRB approval (figure 3).

\section{DISCUSSION}

We assessed the experiences of research activities, awareness of research integrity and factors associated with potentially inappropriate research behaviours by conducting a nationwide survey of physicians in Japan. Half of the physicians had been first authors in a published paper over the past 5 years, and most physicians had experience learning about research integrity, but the reasons for learning were passive, and the recall rate was not high enough. Two-thirds of the physicians had been involved in clinical research at hospitals rather than universities, but their experiences of learning research integrity were lower than those from university hospitals. Appropriate authorship or transparency of organisational relationships were less likely to be recognised than other aspects such as autonomy and safety of subjects or appropriate data management among physicians. One in nine physicians had indulged in copying and pasting or gifted authorship, and passive reasons for learning research integrity were significantly associated with such behaviours.

Most participants in this study had experienced learning about research integrity. The Ministry of Education, Culture, Sports, Science and Technology in Japan revised the guidelines for dealing with fraudulent activities in research in 2014. ${ }^{21}$ According to these guidelines, universities and institutes, including university hospitals, were responsible for improving and managing the environment for conducting research integrity education, and funding agencies requested all funded researchers to be educated on research integrity. As a result, $87 \%$ of research institutes had an educational system for research integrity in place by $2015,{ }^{14}$ and our data showed that 99\% of participants affiliated with university hospitals had this experience. These data indicate that educational opportunities for research integrity are present in university hospitals. However, two-thirds of physicians who conducted clinical research were affiliated with hospitals other than universities, and they were less likely to receive this education compared with physicians at university hospitals. In addition, less than half of the physicians paid attention to the Ethical Guidelines, Clinical Trials Act or other policies.

We hypothesised that the relatively lower penetration rate of education among hospitals other than universities or lower awareness of the guidelines was because current methods of learning research integrity were passive or 


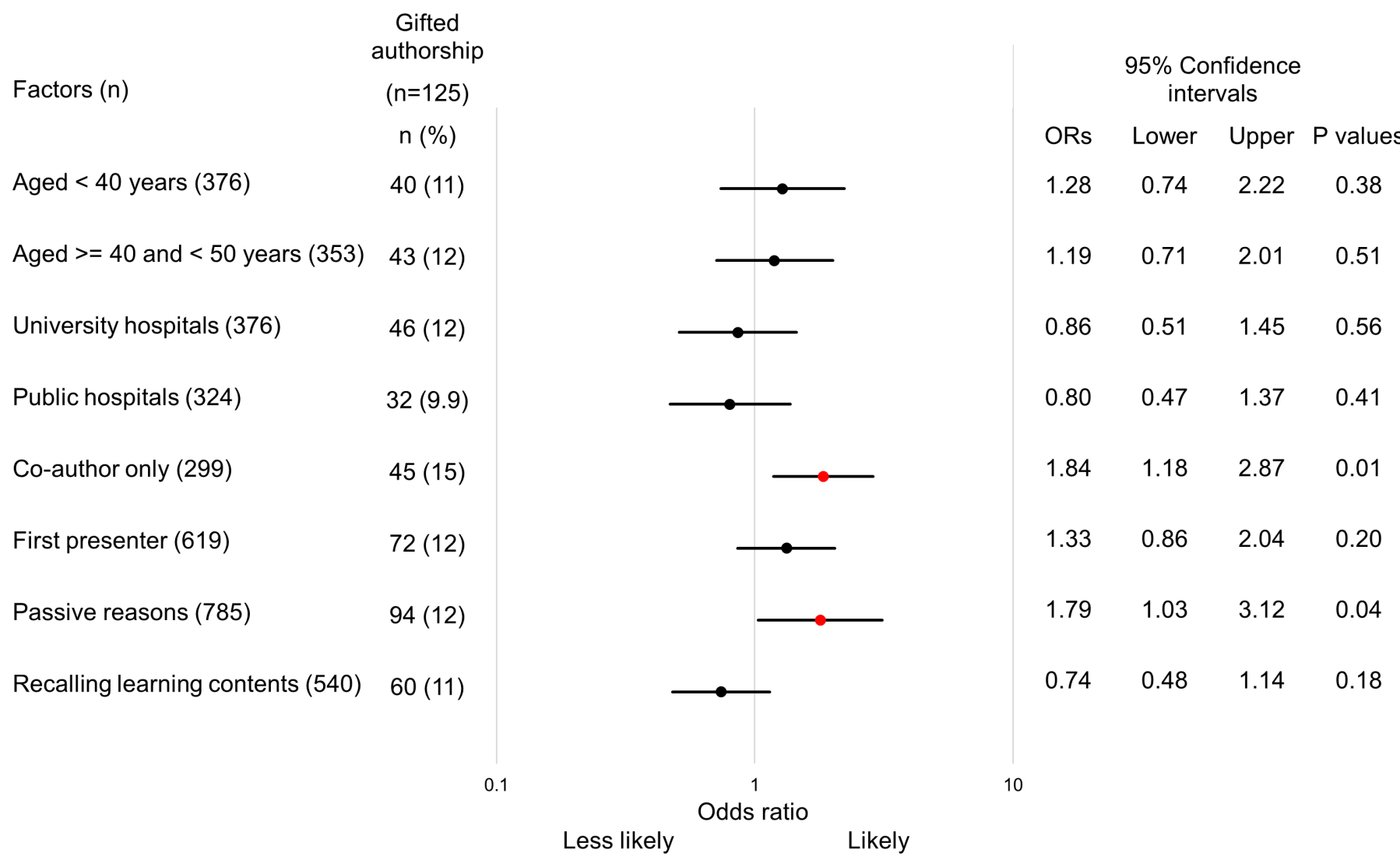

Figure 2 Factors associated with gifted authorship. The horizontal bars indicate the $95 \%$ confidence intervals, and the points on the bars indicate the adjusted odds ratios (ORs). X-axis is an exponential scale.

forced. A majority of participants reported that they had learnt research integrity because it was a requirement of the institution or necessary to obtain approval from the IRB, and those who reported proactive reasons such as necessity or interest were a minority. Participants with experience of the first author tended to have passive reasons for learning, but they recalled the information and were more aware of research integrity policies than those without this experience. In this context, national initiatives on research integrity were satisfactory in Japan, although there are still areas that require reform.

We found that the transparency of organisational relationships was the least known aspect of research integrity. Although only $16 \%$ of physicians who conducted clinical research were aware of it, those who recalled learning content well after learning research integrity or had knowledge of public policies were twice as likely to be aware of it than those who did not. Interpersonal relationships in environments where scientists conduct their work are a factor associated with research misconduct. ${ }^{22}$ Physicians belonging to an organisation may think that the transparency of relationships is not an individual issue. Along with individuals, organisations must also contribute to improving the research environment. ${ }^{23}$ Therefore, learning programmes for research integrity should target the research team as well as individual investigators.

We investigated the factors associated with copying and pasting, gifted authorship and conducting clinical research without IRB approval. These behaviours are discussed at the Collaborative Institutional Training Initiative in the USA so that they can be avoided in research activities, ${ }^{24}$ although they might still be poorly recognised as unethical behaviour. We recognised that researchers outside English-speaking countries sometimes referred to descriptions from articles written in English to write their manuscripts in English. ${ }^{25}$ As the inappropriate behaviour of copying and pasting was also reported in areas where English was the first language, the difficulty of writing in another language was not the sole reason for this behaviour, which implies that this behaviour might be extended to plagiarism. ${ }^{27}$ We demonstrated that younger investigators, those with affiliations other than university hospitals, first presenters at scientific meetings, and those with passive reasons for learning about research integrity, were associated with this type of behaviour. We assumed that younger investigators or those with affiliations other than university hospitals tended to copy and paste because of the lack of experience or opportunities in scientific and academic writing. They may also lack other skills required to conduct quality research, including methodology. These groups should be the key targets when implementing a new strategy for research integrity education in conjunction with research methodology.

The ultimate result of copying and pasting is plagiarism. Because plagiarism check programmes are now widely used by institutions or journals, the incidence of 
Omission of

IRB approval

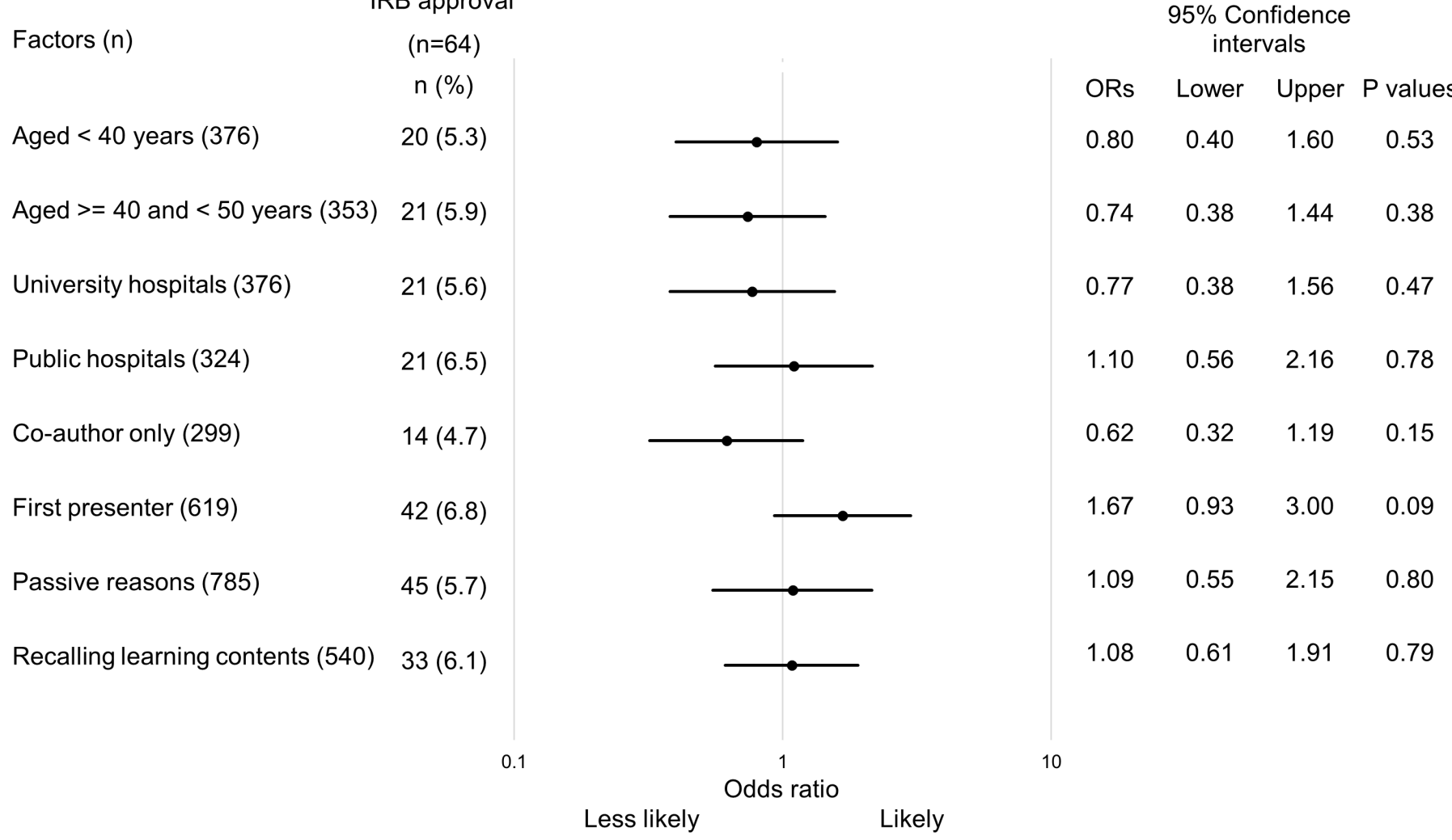

Figure 3 Factors associated with the omission of Institutional Review board (IRB) approval. The horizontal bars indicate the $95 \%$ confidence intervals, and the points on the bars indicate the adjusted odds ratios (ORs). X-axis is an exponential scale.

plagiarism or copying and pasting might not be problematic in the future. However, such programmes might mask the actual behaviour of copying and pasting if many researchers routinely use them. We should thus stress the importance of proactive education of researchers to be aware of research integrity in the era of constantly advancing technology.

The International Committee of Medical Journal Editors has published authorship criteria in medical journals. ${ }^{28}$ However, clinical research often involves multiple physicians with several roles. Therefore, it may be difficult for each of them to fulfil the authorship criteria. ${ }^{29}$ In addition, institutional hierarchy has resulted in passive but forced gifted authorship in the past. With such longstanding customs, as well as poor education in authorship, physicians tend to be gifted co-author status. For this study, we asked only if the participant had received gifted authorship and did not ask whether they had gifted authorship to anyone. This was done to avoid the double count of gifted authorship.

Some researchers might not have known that retrospective studies reviewing medical records do not require IRB approval. Similarly, scientific meetings or conferences also do not require IRB approval for submission or presentation. These situations might result in the continued omission of IRB approval for clinical research. In the multivariable models used in this study, recalling learning content was not significantly associated with any of these potentially inappropriate research behaviours. Therefore, additional proactive education should be considered to change behaviours among physicians who conduct clinical research.

Consistent with previous reports investigating the age distribution of research activities among researchers in all scientific fields, ${ }^{30-32}$ our study found that physicians aged 50 years or older tended to become co-author only. They were more aware of the many aspects of research integrity than the other age groups. Co-authors were likely to be senior authors who acted as mentors for the research group, thus making them responsible for research quality. ${ }^{32}$ Mentoring has been reported to play an important role in preventing research misconduct. ${ }^{33-35}$ The relatively higher awareness of research integrity among senior physicians might be due to having more research experience and perhaps becoming motivated to improve research integrity as a result.

Our findings were supported by a previous report, which suggested that training to reduce research misconduct should be conducted in a laboratory rather than in the classroom. ${ }^{36}$ Professional decision-making in research was reported to be an important element of research integrity that is based on experience. ${ }^{3738}$ Moreover, simple accumulation of research experience risks encouraging individuals to follow their own judgement of research integrity or past customs. Therefore, proactive learning of research integrity is desirable when conducting actual 
clinical research. There were several programmes to train practising physicians about clinical research skills, where the experiences of learners became the primary resource of teaching. ${ }^{39} 40$ This style of education should be employed to teach physicians about research integrity in the context of clinical research. Although this study sampled physicians conducting research, the importance of research integrity and its education should be universal for other healthcare professionals as well as scientists. The findings of this study should be shared with other scientific fields.

This study had several limitations that are inherent to the study design. Most importantly, the physicians in this cross-sectional study were sampled from internet panels. Although we conducted stratified sampling through geographic and subspecialty distributions, the registered physicians could still have been different from general physicians. However, $35 \%$ of physicians belonged to university hospitals or institutes in this study, and this figure was consistent with $27 \%$ from the physicians' census. ${ }^{41}$ The age distribution was similar to that of the same census. ${ }^{41}$ Therefore, our samples should be considered reflective of the actual situation in Japan. Second, we presented many questionnaire items and compared them between the characteristic variables. Although the accompanying $p$ values represented the degree of reliability of associations, they should be interpreted cautiously and considered exploratory. Finally, the results of the crosssectional study did not always reflect actual behaviours. Reporting biases might exist because we asked about delicate experiences related to potentially inappropriate research behaviours. However, other methods, such as direct observations, were flawed by the Hawthorne effect. Therefore, we anonymously conducted this study so that the participants could report their actual behaviours without the risk of blame, although recall bias was unavoidable.

\section{CONCLUSION}

A nationwide cross-sectional study showed that most physicians with clinical research experience had learnt about research integrity, but that awareness was not high enough in some aspects of research integrity and varied with the background of physicians. Potentially inappropriate research behaviours existed among physicians, including copying and pasting, gifted authorship and omission of IRB approval. Passive reasons for learning about research integrity were found to be associated with these behaviours. Additional proactive education should be considered to improve the research practices of physicians who conduct clinical research.

Acknowledgements We are indebted to Ms Kaori Tanaka (Macromill Carenet) for her support in conducting the cross-sectional study, as well as the anonymous physicians who participated in this research.

Contributors TM had full access to all the data in the study and took responsibility for the integrity of the data and the accuracy of the data analysis. Concept, design and analysis or interpretation of data: all authors. Acquisition: RN, JT and TM.
Drafting of the manuscript and statistical analysis: RN and TM. Critical revision of the manuscript for important intellectual content: JT, MS, KU, MH, NK, FS, TN, SK, SY and SU. Administrative, technical or material support: JT, MS, KU, MH, NK, FS, TN, SK, SY, SU and TM. Supervision: SK, SY, SU and TM.

Funding This study was supported by the Japan Agency for Medical Research and Development under grant numbers JP190a0310004h0001, JP20oa0310004h0002 and JP210a0310004h0003 (led by TM entitled 'Development of proactive learning program of research ethics applicable in clinical research training').

Competing interests None declared.

Patient and public involvement statement Neither patients nor the public were involved in the design, data collection, analyses, and reporting of this manuscript.

Participants consent for publication Consent obtained directly from participant(s)

Ethics approval This study was approved by the Ethics Committee of Hyogo College of Medicine (approval number: 3413 ). Electrical written informed consent was obtained from all participants.

Provenance and peer review Not commissioned; externally peer reviewed.

Data availability statement Data are available upon reasonable request. The data that support the findings of this study are available from the corresponding author upon reasonable request.

Supplemental material This content has been supplied by the author(s). It has not been vetted by BMJ Publishing Group Limited (BMJ) and may not have been peer-reviewed. Any opinions or recommendations discussed are solely those of the author(s) and are not endorsed by BMJ. BMJ disclaims all liability and responsibility arising from any reliance placed on the content. Where the content includes any translated material, BMJ does not warrant the accuracy and reliability of the translations (including but not limited to local regulations, clinical guidelines, terminology, drug names and drug dosages), and is not responsible for any error and/or omissions arising from translation and adaptation or otherwise.

Open access This is an open access article distributed in accordance with the Creative Commons Attribution Non Commercial (CC BY-NC 4.0) license, which permits others to distribute, remix, adapt, build upon this work non-commercially, and license their derivative works on different terms, provided the original work is properly cited, appropriate credit is given, any changes made indicated, and the use is non-commercial. See: http://creativecommons.org/licenses/by-nc/4.0/.

\section{ORCID iDs}

Jiro Takeuchi http://orcid.org/0000-0002-4904-1693

Fumihiro Sakakibara http://orcid.org/0000-0001-5866-6743

Takeshi Morimoto http://orcid.org/0000-0002-6844-739X

\section{REFERENCES}

1 Foundation TWC on RI. Mission of the WCRIF. Available: https:// www.wcrif.org/foundation/mission [Accessed 11 Aug 2021].

2 Steneck NH. Fostering integrity in research: definitions, current knowledge, and future directions. Sci Eng Ethics 2006;12:53-74.

3 Office of Sciene and Technology Policy. Federal research misconduct policy. 2000;65:76260-4.

4 Resnik DB, Rasmussen LM, Kissling GE. An international study of research misconduct policies. Account Res 2015;22:249-66.

5 Fanelli D. How many scientists fabricate and falsify research? A systematic review and meta-analysis of survey data. PLoS One 2009; 4:e5738.

6 National Academy of Sciences, National Academy of Engineering and I of M. Responsible science: ensuring the integrity of the research process. Washington DC: The National Academies press, 1992.

7 John LK, Loewenstein G, Prelec D. Measuring the prevalence of questionable research practices with incentives for truth telling. Psychol Sci 2012;23:524-32.

8 Marusic A, Wager E, Utrobicic A, et al. Interventions to prevent misconduct and promote integrity in research and publication. Cochrane Database Syst Rev 2016;4:MR000038.

9 Hofmann B, Bredahl Jensen L, Eriksen MB, et al. Research integrity among PHD students at the faculty of medicine: a comparison of three Scandinavian universities. J Empir Res Hum Res Ethics 2020;15:320-9.

10 Gardner W, Lidz CW, Hartwig KC. Authors' reports about research integrity problems in clinical trials. Contemp Clin Trials 2005;26:244-51. 
11 Rosenstein DL, DeRenzo EG. Professional integrity in clinical research. Ethical Challenges Hum Res Sel Essays 2012;280:1449-54.

12 Brody H, Miller FG. The clinician-investigator: unavoidable but manageable tension. Kennedy Inst Ethics J 2004;13:329-46.

13 Cattorini P, Mordacci R. The physician as caregiver and researcher. Thyroidology 1993;5:73-6.

14 Ministry of Education, Culture, Sports Science and Technology. Results of the 2015 Performance Status Survey based on the Guidelines for Responding to Misconduct in Research [online], 2015. Available: https://www.mext.go.jp/content/20200122-mxt kouhou02000004307_01.pdf [Accessed 11 Aug 2021].

15 Breen KJ. Misconduct in medical research: whose responsibility? Intern Med J 2003;33:186-91.

16 Artino AR, Driessen EW, Maggio LA. Ethical Shades of gray: international frequency of scientific misconduct and questionable research practices in health professions education. Acad Med 2019;94:76-84.

17 Japan Agency for Medical Research and Development. Casebook for fair research activities, 2017

18 Ministry of Education, Culture, Sports Science and Technology, Ministry of Health Labour and Welfare. Ethical guidelines for medical and health research involving human subjects [online], 2017. Available: https://www.lifescience.mext.go.jp/files/pdf/n2181_01.pdf [Accessed 11 Aug 2021].

19 Ministry of Health Labour and Welfare. Clinical Trials Act [online], 2017. Available: https://www.mhlw.go.jp/file/06-Seisakujouhou10800000-Iseikyoku/0000213334.pdf [Accessed 11 Aug 2021].

20 Lee JW, Jones PS, Mineyama Y, et al. Cultural differences in responses to a Likert scale. Res Nurs Health 2002;25:295-306.

21 Ministry of Education, Culture, Sports Science and Technology. New quidelines for responding to misconduct in research, 2014.

22 Davis MS, Riske-Morris M, Diaz SR. Causal factors implicated in research misconduct: evidence from ori case files. Sci Eng Ethics 2007;13:395-414.

23 National Academies of Sciences, Engineering, Medecine. Fostering Integrity in Research A Consensus Study Report of [online] 2017.

24 Braunschweiger P, Goodman KW. The CITI program: an international online resource for education in human subjects protection and the responsible conduct of research. Acad Med 2007;82:861-4.

25 Gasparyan AY, Nurmashev B, Seksenbayev B, et al. Plagiarism in the context of education and evolving detection strategies. J Korean Med Sci 2017;32:1220-7.
26 Yilmaz I. Plagiarism ? No, we're just borrowing better English Biosafety risk in health lab Need to strike balance with industry academia rules Plagiarism : text-matching program offers an answer. Nature 2007

27 Horrom TA. The perils of copy and paste: Plagiarism in scientific publishing. J Rehabil Res Dev 2012;49:vii-xii.

28 Ali MJ. ICMJE criteria for authorship: why the criticisms are not justified? Graefe's Arch Clin Exp Ophthalmol 2021;259:289-90.

29 Afifi MM. Credit and disputes. Saudi Med J 2004;25:1742-3.

30 Costas R, Bordons M. Do age and professional RANK influence the order of authorship in scientific publications? Some evidence from a micro-level perspective. Scientometrics 2011;88:145-61.

31 Gingras $Y$, Larivière $\mathrm{V}$, Macaluso $\mathrm{B}$, et al. The effects of aging on researchers' publication and citation patterns. PLoS One 2008;3:e4048.

32 Liang L, Guo Y, Davis M. Collaborative patterns and age structures in Chinese publications. Scientometrics 2002;54:473-89.

33 Wocial LD. The role of mentors in promoting integrity and preventing scientific misconduct in nursing research. J Prof Nurs 1995;11:276-80.

34 Kumar MN. A theoretical comparison of the models of prevention of research misconduct. Account Res 2010;17:51-66.

35 Khanyile TD, Duma S, Fakude LP, et al. Research integrity and misconduct: a clarification of the concepts. Curationis 2006;29:40-5.

36 Kornfeld DS. Integrity training: misconduct's source. Science 2013;340:1403-4.

37 DuBois JM, Chibnall JT, Tait RC, et al. Professional decision-making in research (PDR): the validity of a new measure. Sci Eng Ethics 2016;22:391-416.

38 Mumford MD, Connelly S, Murphy ST, et al. Field and experience influences on ethical decision-making in the sciences. Ethics Behav 2009;19:263-89.

39 Goldman L, Cook EF, Orav J, et al. Research training in clinical effectiveness: replacing "in my experience" with rigorous clinical investigation. Clin Res 1990;38:686-93.

40 Morimoto T. Training program for healthcare professionals who conduct clinical researches. Jpn J Clin Pharmacol Ther 2011;42:295-6.

41 Ministry of Health Labour and Welfare. Survey of physicians, dentists and pharmacists, 2018. Available: https://www.mhlw.go. jp/english/database/db-hss/dl/spdp_2018.pdf [Accessed 13 Apr 2021] 